\title{
ABSTRACT SUBSTANTIVE-EQUALITY - A CRITICAL RACE THEORY ANALYSIS OF 'HATE SPEECH' AS CONSIDERED IN THE SAHRC-REPORT ON UTTERANCES MADE BY JULIUS MALEMA
}

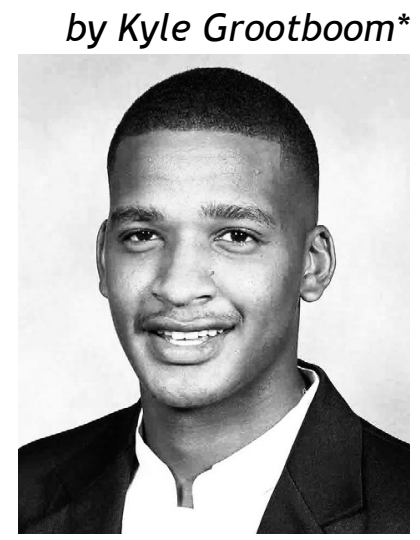

'Thus, with regard to the application of justice it accords primacy to the concrete, the world of the living. In this sense it is different from Western legal thought which apparently stresses the abstract."1

\section{Introduction}

In the following article I will critically analyse the concept of hate speech as it was considered in the South African Human Rights

* Third year LLB Law student at the University of Pretoria. This article is an adapted version of an essay submitted by me in completion of the module JUR 310 under Dr Joel Modiri. In this article I critique hate speech laws, a narrow view of racism and the fallibility of these concepts in contributing to a more substantially equal society. I would like to thank Primrose ER Kurasha, Frieda Shifotoka and Thato P Maruapula for helping me in making my article more presentable through their feedback and engagement. All errors and shortcomings are undeniably my own. To my mother Daleen Grootboom and brother Cohen Grootboom, I send a thousand kisses. And lastly, in the words of Earl Sweatshirt: 'There's not a black woman i can't thank!'.

1 M Ramose 'an African Perspective on Justice and Race' (2001) polylog: Forum for Intellectual Philosophy http://them.polylog.org/3/frm-en.htm (accessed 30 August 2019). 
Commission's (the 'Commission') report on utterances made by Julius Malema (the 'report'). ${ }^{2}$ The critique will be delivered by way of Critical Race Theory (CRT) as I aim to illustrate the Commission's narrow interpretation of racism in light of hate speech. Because the Commission relies on an array of court judgments and equality legislation to form its equality jurisprudence on hate speech, my critique will also set out to show that the Commission's equality jurisprudence is reflective of the Constitution and the courts' narrow understanding of racism. I aim to argue that a narrow understanding of racism leads to a very abstract equality jurisprudence.

I will illustrate that an equal emphasis on substantive equality, if not more, is necessary to fully address socio-economic inequality. This is so because I argue that hate speech manifests as a result of the substantive inequality amongst people. A more adequate solution would therefore be to address substantive inequality, instead of remedying hate speech, which is merely a consequence. ${ }^{3}$

I will use CRT to analyse hate speech as it was considered in the report, because as postulated above, inequality in South Africa is for the most part racialised because of the country's colonial apartheid past. ${ }^{4}$ I will rely on Derrick Bell's article entitled 'Who's afraid of Critical Race Theory?' in my understanding and application of critical race theory throughout my analysis. ${ }^{5}$ The aforementioned article offers an approach to critique the law from the perspective of the black oppressed. It primarily sets out how the law enables and entrenches racial oppression. It also offers techniques for a critical race critique of the law. ${ }^{6}$

I will make use of Transformative Constitutionalism and Decolonisation as theories that aim to address and redress the injustices of the past. Transformative constitutionalism, according to Karl Klare in the article 'Legal Culture and Transformative Constitutionalism', recognises the injustices of the past and believes that the Constitution can be used as a tool to address and redress those injustices if interpreted in a transformative way. ${ }^{7}$ I aim to illustrate how Transformative Constitutionalism aligns itself with a narrow understanding of racism and thus abstract equality. Decolonisation takes the legal reform debate much further in

2 The South African Human Rights Commission ('Commission') 'Report on utterances made by Julius Malema and Another' (March 2019).

3 J Modiri 'The “event” of racism' Daily Maverick 17 November 2016 https://www. dailymaverick.co.za/opinionista/2016-11-17-the-event-of-racism/ (accessed on 16 September 2019).

4 D Bell 'Who's afraid of critical race theory' (1995) University of Illinois Law Review 893 - 910.

5 Bell (n 4) $893-895$.

6 Bell (n 4) 899. Also note 'Black people' in this essay alludes to African, Coloured and Indian people in South Africa.

7 K Klare 'Legal Culture and Transformative Constitutionalism' (1998) 14 South African Journal on Human Rights at $146-188$. 
asserting and interrogating the law, equality and notions of what it means to be a human being from deeply African perspectives. ${ }^{8}$ I will discuss decolonisation from the perspectives of Kwasi Wiredu's 'Conceptual Decolonization as an Imperative in Contemporary African Philosophy: Some Personal Reflections' and T Serequeberhan's 'African Philosophy as the Practice of Resistance'. ${ }^{9}$ It is my aim to show that decolonisation much like CRT aligns itself with a broader understanding of racism and thus a substantive notion of equality.

\section{A brief differentiation between abstract and substantive - equality}

The concepts of 'substantive rights and equality' are established legal terms especially in constitutional jurisprudence and it alludes to rights such as that in the Bill of Rights as opposed to procedural rights. ${ }^{10}$ For the purposes of this essay however, a differentiation is drawn between abstract and substantive rights and equality. The two concepts are also more philosophically defined, instead of legally defined. Where abstract rights and equality relates to a detachment from the lived, substantive and socio-economic conditions of people. ${ }^{11}$ Abstract rights can thus be describe as political rights or the protection of rights of which the objects are not possessed and accessible by people. ${ }^{12}$ Furthermore, substantive equality, in this essay relates to economic rights which have concrete and material manifestations, like property rights, food and healthcare. Substantive rights and equality as understood in this essay necessarily place a positive obligation on the state.

The following serves as an example to illustrate how substantive and abstract rights and equality are understood in this essay; the right to access to the courts, is entrenched in the Bill of Rights of the South African Constitution and is traditionally seen as a substantive right. In this article however, it would be seen as an abstract right since a lot of people to do not have access to the courts for a variety of reasons such as, location and affordability as will be discussed below. Thus, although various rights are substantive on paper, for the purposes of this essay, they will only become substantive once they manifest and

8 Ramose (n 1) 1.

9 K Wiredu 'Conceptual Decolonization as an Imperative in Contemporary African Philosophy: Some Personal Reflections' (2002) 36 Rue Descartes 53 - 64. See also T Serequeberhan 'African Philosophy as the Practice of Resistance' (2009) 4 Journal of Philosophy: A Cross-disciplinary Inquiry 44-5.

10 Klare (n 7) 54.

11 A Kok 'The Promotion of Equality and Prevention of Unfair Discrimination Act 4 of 2000: Court-driven or legislature-driven societal transformation?' (2008) 1 Stellenbosch Law Review at 133.

12 CRM Dlamini 'Equality or justice? Section 2 of the Constitution revisited - Part I' 27(2) Journal for Juridical Science 2002 at $15-32$. 
become a concrete reality for people, however, until then they will be deemed abstract, for the purposes of this essay. It is also fitting to state at this stage of the introduction that 'post'-apartheid South Africa is often cited by scholars as the political emancipation of black people but not the substantive, economic emancipation. ${ }^{13}$

In this essay, abstract rights mean rights and in turn a notion of equality that is detached from the reality of racialised inequality, rights which are unattainable by the majority of oppressed black people and rights which merely exist as ideals, as will be illustrated below. ${ }^{14}$ This would be rights such as freedom of expression and dignity. It is posited that abstract rights and equality is reflective of a narrow view of race and racism. A narrow view of racism, as critiqued by the concept of CRT, is a view that sees racism as determinable individual acts of racial bigotry towards people of a specific racial group. CRT, however, defines racism as the systemic oppression of black people for the benefit of white privilege. The concept of hate speech (insofar as it is racialised, as will be critiqued) is thus one of the repercussions of the aforementioned narrow view of racism and abstract equality.

\section{Summary of the SAHRC-Report on hate speech}

The Commission was tasked with investing four instances of alleged hate speech made by Julius Malema and one instance of hate speech made by Godrich Gardee during electioneering campaigns and political rallies dating from 2016 TO 2018. ${ }^{15}$

The Commission first delved into the constitutional provisions relating to hate speech. ${ }^{16}$ The Commission stated that the right to human dignity informs both the right to equality as guaranteed in section 2 of the Constitution, and the right to freedom of expression as guaranteed in section 16(1) of the Constitution. ${ }^{17}$ It was held that the freedom of expression is not absolute but a balance needs to be found between freedom of expression and the right to equality. ${ }^{18}$ It flows that this balance is found in section 16(2) of the Constitution, which holds that harmful expression does not enjoy constitutional https://www.academia.edu/27141915/THE_NGUNI_PERSPECTIVE_OF_UBUNTU (accessed 5 September 2019).

15 The SAHRC Report (n 2) 1 - 3.

16 The SAHRC Report (n 2) 5.

17 The SAHRC Report (n 2 ) 2.

18 As above. 
protection, and furthermore in the section, the 'advocacy of hatred' is expressly excluded in section $16(2)(c) .{ }^{19}$

The 'advocacy of hatred' i.e. hate speech is not constitutionally protected and is further statutorily prohibited by section 10 of Promotion of Equality and Prevention of Discrimination Act (PEPUDA). ${ }^{20}$ The Commission's report states that section 10 of PEPUDA is a limitation in terms of section 36 of the Constitution. ${ }^{21} \mathrm{~A}$ conjunctive interpretation of section 10 of PEPUDA or a combination between a conjunctive and disjunctive approach saves it from being an unlawful limitation in terms of section 36 of the Constitution. A conjunctive reading would require that all of the elements of hate speech be present for it to constitute such. This means that expression must be 'hurtful and harmful and promote hatred' for it to be a hate speech. A disjunctive reading requires that hurts may be 'hurtful or harmful or promote hatred' for the utterance in question to constitute hate speech. It is stated in the report that there is currently no precedent for which reading would be more appropriate. The Commission thus proceeded to use both readings; this means that the Commission used either a disjunctive reading or a conjunctive reading depending on each one's relevance. The commission also stated that an objective test is required for hate speech and this entails that hate speech would be determined without taking into consideration the subjective intentions of the person who utters the words. ${ }^{22}$

The Commission then pointed out that establishing context when it comes to hate speech is pertinent and very much a requirement in terms of section 3(3) of PEPUDA. ${ }^{23}$ It was stated that the factual, social and historical context of a statement needs to be considered and the fact that an alleged expression of hate speech is directed at vulnerable groups or individuals would make a finding to that Effect more likely. ${ }^{24}$

Afterwards the Commission applied its jurisprudence of hate speech to the five statements.

The first statement was made by Julius Malema in 2016 with regard to land dispossession and white people which reads:

They found peaceful Africans here. They killed them. They slaughtered them like animals. We are not calling for the slaughtering of white people, at least for now. What we are calling for is the peaceful occupation of the land and we don't owe anyone an apology for that... 25

19 The SAHRC Report (n 2) 5 - 7.

20 As above.

21 As above.

22 The SAHRC Report (n 2) 7 - 15.

23 The SAHRC Report (n 2) 5.

24 The SAHRC Report (n 2) 15.

25 The SAHRC Report (n 2) $17-20$. 
The Commission held that, viewed in a historical, social and factual context, the statement does not amount to hate speech, as the statement was made with regard to land dispossession and not intended to incite any harm towards white people. ${ }^{26}$

The second statement was made by Julius Malema in August 2017 and reads:

Here in Durban, here in $\mathrm{KZN}$, everything strategic is given to Indian families ... every big tender is given to Indian families ... they are the ones who own everything strategic here in KZN.

We don't have a problem: We are saying share with our people.

We also want to call upon our fellow Indians here in Natal to respect Africans, they are ill-treating them. We don't want that to continue here in Natal. They are treating them worse than Afrikaaners will do.

This is not an anti-Indian statement, it's the truth. If we tell whites the truth; if we tell blacks the truth, we can as well tell Indians the truth. They must treat our people properly here in Kwa-Zulu Natal. ${ }^{27}$

Through a conjunctive reading and an objective, contextual assessment of the statement, the Commission found it not constitutive of hate speech. A further disjunctive reading also found the statement not to be hate speech. ${ }^{28}$

The third statement was the singing of the song 'kiss the boer' (a rewording of the song 'kill the boer') by Julius Malema on 21 March 2018. The Commission interestingly found that the singing of this song does not amount to hate speech, on an objectively construed meaning of the words of the song, from a factual and political perspective. ${ }^{29}$ The Commission found this notwithstanding a contradictory finding of the Equality Court on the same song a few years back. ${ }^{30}$

The fourth statement was made by Julius Malema on 16 June 2018 was also found not to constitute hate speech from an objective and contextual reading; ${ }^{31}$ it read as follows:

We were not all oppressed the same. Indians had all sorts of resources Africans didn't have, Coloureds as well... The majority of Indians hate Africans. The majority of Indians are racist. I'm not saying all, I'm saying majority. ${ }^{32}$

The fifth statement was a social media post made by Mr Godrich Gardee in which he called a fellow DA Member of Parliament, Mmusi Maimane, a 'garden boy' during a parliamentary sitting in May 2018. ${ }^{33}$

26 As above

27 The SAHRC Report (n 2) 20 - 22.

28 As above.

29 The SAHRC Report (n 2) 24.

30 The SAHRC Report (n 2) 22 - 26.

31 The SAHRC Report (n 2) p $26-28$.

32 As above.

33 The SAHRC Report (n 2) 27. 
From a contextual and objective reading, the court also found this statement as not constituting hate speech. ${ }^{34}$

\section{Critical analysis of hate speech as considered in the Report}

\subsection{Critical Race Theory}

As stated above, my critical analysis of the Commission's report will be done by way of CRT). Although my understanding and application of CRT will be mainly founded on Derrick Bell's article 'Who's afraid of Critical Race Theory', 35 it is also influenced by two of Modiri's texts on this theory. ${ }^{36}$

CRT is a field of study that produces mechanisms to critically analyse the dynamics of race and racism within a legal system. ${ }^{37}$ The idea that white supremacy is a far right ideology in as much as the actions of white extremists and the occasional uttering of racially derogatory terms or statements is central to CRT. Racism, for a Critical Race theorist, is a consequence of white supremacy. White supremacy is the structural composition of a society that systematically prejudices black people in a variety of ways for the benefit and conservation of white privilege. ${ }^{38}$ Racism is thus a consequence of the preservation of white privilege.

Modiri situates CRT in a 'post'-apartheid South African context. He then suggests three mains ideals for it within this context. It should firstly be critical of the law and existing legal institutions that sustains white supremacist dogma. It should further analyse the legally crystalised economic inequality, poverty and distribution of wealth along racial lines. It should lastly dwell in the complexities of race, culture and identity of social and political life in South Africa. ${ }^{39}$ It is therefore necessary that CRT, according to Modiri, should be equally as anti-racist as it is anti-capitalist since the two-function hand-inhand. Lastly, Modiri suggests that CRT can be utilised as a postapartheid jurisprudence. ${ }^{40}$

What follows now is a CRT critique of hate speech as considered in the Commission's report on Julius Malema. I will first critique the

34 The SAHRC Report (n 2) 17 - 30.

35 Bell (n 4) $893-910$.

36 Modiri (n 13) 224. See also J Modiri 'Race realism and critique the politics of race in AfriForum v Malema in the (In)Equality Court' (2013) 130(2) SALJ $274-293$. See also J Modiri 'The colour of law, power and knowledge: Introducing Critical Race Theory in (Post-) Apartheid South Africa' (2012) 28 SAHRJ 405 - 436.

Bell (n 4) 901 - 902. See also Modiri (n 36) 285 \& 286.

38 Bell (n 4) 901 - 902. See also Modiri (n 36) 288.

39 Modiri (n 13) 258.

40 Modiri (n 36) 405 - 437. 
two provisions that hate speech is grounded on namely, freedom of expression and equality. I will then critique hate speech as defined in section 10 of PEPUDA. Lastly, I will critique certain terms and judgments referenced in the report.

\subsection{Critique}

In paragraph 2.1.4 of the Commission's report the case of Khumalo $v$ Holomisa was referenced in stating that when a matter of hate speech considered a balance between Freedom of Expression and Equality ought to be established. ${ }^{41}$ Freedom of expression is founded in section 16(1) of the Constitution, which holds the following:

Everyone has the right to freedom of expression, which includes -

(a) freedom of the press and other media;

(b) freedom to receive or impart information or ideas;

(c) freedom of artistic creativity; and

(d) academic freedom and freedom of scientific research. ${ }^{42}$

The Commission's report further states that political speech is central to the freedom of expression, while other types of speech falls in the realm of the abstract in the sense that, it has less societal value and can therefore be easily limited as was the case in De Reuck v Director of Public Prosecutions. ${ }^{43}$ It is clear from the above that freedom of expression is only helpful from a CRT perspective to the extent that it can create awareness of the substantive condition of the black oppressed. $^{44}$ that:

Equality is founded in section 2 of the Constitution and it holds

(1) Everyone is equal before the law and has the right to equal protection and benefit of the law.

(2) Equality includes the full and equal enjoyment of all rights and freedoms. To promote the achievement of equality, legislative and other measures designed to protect or advance persons, or categories of persons, disadvantaged by unfair discrimination may be taken.

(3) The state may not unfairly discriminate directly or indirectly against anyone on one or more grounds, including race, gender, sex, pregnancy, marital status, ethnic or social origin, colour, sexual orientation, age, disability, religion, conscience, belief, culture, language and birth.

41 The SAHRC Report (n 2) para 2.1.4. See also Khumalo v Holomisa [2002] ZACC 12; 2002 (5) SA 401.

$42 \mathrm{Sec}$ 16(1) of the Constitution of the Republic of South Africa, 1996.

43 The SAHRC Report (n 2) para 2.1.4. See also De Reuck $v$ Director of Public Prosecutions (CCT5/03) [2003] ZACC.

44 S Conradie 'Critical Race Theory and the question of safety in dialogues on race' (2016) 36(1) Acta Theologica 5 - 26. See also G Barrie 'Freedom of expression and campus protests' (2017) 38(3) Obiter 623 - 631 . 
(4) No person may unfairly discriminate directly or indirectly against anyone on one or more grounds in terms of subsection (3). National legislation must be enacted to prevent or prohibit unfair discrimination.

(5) Discrimination on one or more of the grounds listed in subsection (3) is unfair unless it is established that the discrimination is fair. ${ }^{45}$

From a CRT perspective, the above quoted equality clause in the Constitution can be said to merely exist for the protection and interest of white privilege and insofar as it seeks to protect black people against the 'injustices of the past,' it does so on a superfluous, abstract level that is merely contingent on the underlying substantive unequal conditions of black people, as will be discussed below. ${ }^{46}$

Kok observes the development of the Constitutional Court's equality jurisprudence as peculiar. He argues that because courts function on a complaint-driven system, black people, as the ones that ought to benefit from equality laws, in light of South Africa's past, do not necessarily benefit from equality laws for an array of reasons. ${ }^{47}$ One being the inability of black people to gain access to the courts as they cannot afford the legal fees. ${ }^{48}$ This argument further contributes to the abstract nature of the courts themselves in the daily experiences of black people. Another question this raises is whether equality laws were in fact enacted for the benefit of black people. Dlamini highlights the potential to mislead this clause has, as it does not necessarily entail total equality or equality in any form for that matter, but rather the idea of fairness and justice which is more related to dignity, which all are very abstract concepts to a significant extent. ${ }^{49}$ This is not to say that fairness, justice and dignity will not aid black people in the quest for economic emancipation, but it does not speak to the core issue of substantive inequality, poverty and material living conditions. ${ }^{50}$

In section 2(1) of the Constitution above, it states that 'everyone is equal before the law', however, from the perspective of CRT the wording of this section is very peculiar in the sense that it does not mirror the reality of racial inequality. ${ }^{51}$ One can thus deduce from this that despite the reality of racial inequality, in the eyes of the law black and white people are seen as equal. This proves that the law and the equality clause in particular is very much detached from reality, as its conception of equality roams in the abstract domains of justice

Sec 9 of the Constitution (n 43).

Bell (n 4) 901 - 902 \&906. See also Modiri (n 37) 275. See also The Preamble of the Constitution (n 43).

Kok (n 11) 133.

As above.

Dlamini (n 12) 14 - 25.

Modiri (n 13) 246.

Modiri ( $n$ 36) 246. See also S Veitch et al (eds) Jurisprudence - Themes and Concepts 2ed. (2012) $123-131$. See also sec 9(1) of the Constitution (n 43). 
and fairness despite the substantive differences in the living conditions of people, the people it seeks to protect. The further wording of 'enjoyment and protection of rights' can be interpreted to the benefit of white interest as black people generally don't have a lot of substantive rights to be protected or enjoyed. ${ }^{52}$ The words in section 2(2) that certain people are to be advanced should therefore be taken very seriously and interpreted in light of black people, amongst others, needing to be substantively advanced out of the position of the unequal. 53

The wording of section 2(3) to (5) of the Constitution also places a negative obligation on the state with regard to equality and this, to a critical race theorist, can be construed as a non-interference with the status quo; the status quo being the substantive inequality of black people. The critique of non-interference with the unequal status quo is substantiated by this clause not placing a positive obligation on the state or on people to actively see that the substantive inequality amongst people be addressed and redressed. ${ }^{54}$

Thus, on careful reflection, the requirement that a balance between the abstract notion of freedom of expression and the abstract notion of equality should be found when considering a matter of hate speech, concludes in hate speech being abstract. I do not argue that hate speech should not be outlawed. I do argue however that if the purpose of hate speech laws is to achieve equality, then the substantive unequal realities of people should be addressed and not the hate speech, which is merely a manifestation of the former. It is here where the ideas of Butler find applicability:

The utterances of hate speech are part of the continuous and uninterrupted process to which we are subjected, an on-going subjection (assujetissement) that is the very operation of interpellation, that continually repeated action of discourse by which subjects are formed in subjugation. Those offensive terms that mark out a discursive place of violation precede and occasion the utterance by which they are enacted; the utterance is the occasion for the renewal of that interpellating operation. Indeed, that operation is only instanced by the 'verbal conduct'; but the operation of interpellation happens with or without such conduct.

The responsibility of the speaker ... [consists in] negotiating the legacies of usage that constrain and enable that speaker's speech. ${ }^{55}$

From the above quotation I note that even in its abstractness, hate speech is only useful insofar as it illustrates that the "hearts and

$52 \operatorname{Sec} 9(1)$ of the Constitution (n 43).

53 As above.

54 Bell (n 4) 906. See also Modiri (n 36) 281. See also secs 9(3)-(5) of the Constitution (n 43).

55 J Butler 'Excitable speech: A politics of the performative' (1997) 127. See also Modiri (n 37) 280. 
minds" of people in the society are not yet transformed; real transformation vests in the underlying substantive conditions which enable hate speech.

What hate speech laws also do is create the perception that racism and discrimination are isolated incidents. It has already been stated that racism and discrimination is embedded in the functioning of a white supremacist society. ${ }^{56}$ It has also been stated that for CRT, 'post'-apartheid South Africa is such a society as white privilege and interests are protected to the detriment of the black oppressed. It has further been stated that racism is a consequence of white supremacy and although hate speech is not synonymous with racism (systematic racism at least), a racial slur can constitute hate speech if it meets the requirements of section 10 of PEPUDA. ${ }^{57}$

When looking at the objective test (paragraph 4.4 of the report), the debate between disjunctive or conjunctive (paragraph 4.2.1) and the necessity for context (paragraph 5), the interpreter be it a judge or a commissioner will then come to the conclusion that a certain statement does or does not constitute hate speech as seen in the report. ${ }^{58}$ Racial slurs are also commonly seen as acts of racism. ${ }^{59}$ Therefore, in identifying certain acts of racism as hate speech, it alludes to the idea that acts of racism can be identified and isolated. This idea that hate speech can be identified and isolated gives light to a narrow view of racism which is contrary to the CRT view that racism is systemic inequality. ${ }^{60}$ This narrow view of racism is thus abstract in the sense that it does not address the systemic inequality wherein racism vests itself.

This leads to hate speech being very individualistic whereas inequality and racism is more systemic as explained. ${ }^{61}$ In isolating a certain instance or statement of racial hate speech one inevitably implicates a certain individual or group of individuals as wrongdoers. The concept of hate speech also implies that both black and white people can be racist, in instances where hate speech is made in a racial context of course. This is the subject matter of statements four and five, (in paragraphs 10.2 and 11.5 ) of the report. ${ }^{62}$ From a CRT perspective racism is not defined by utterances therefore, certain 'wrongdoing individuals' cannot be found guilty of racism as racism exists within a broader system of a society functioning under white

56 Modiri (n 36) 288. See also Kok (n 11) 133.

57 The SAHRC Report (n 2) 4.

58 As above.

59 J Modiri 'The "event” of racism' Daily Maverick 17 November 2016 https://www. dailymaverick.co.za/opinionista/2016-11-17-the-event-of-racism/ (accessed on 16 September 2019).

60 Bell (n 4) 901 - 906. See also Modiri (n 37) 284 \& 288.

61 As above. See also Modiri (n 3) 225.

62 The SAHRC Report (n 2) 10. 
supremacy. The utterer and the utterance for CRT is irrelevant, as it is the broader system that needs change. ${ }^{63}$

In paragraph 4.8 it states that section 10 of PEPUDA requires an objective test to establish hate speech. It further goes on to say that objectivity is determined through 'reasonableness'. ${ }^{4}$ The legal concept of 'reasonable', as pointed out by Modiri, is problematic through the lens of CRT since it alludes to the idea of the reasonable man being the heterosexual, white male. ${ }^{65}$ Everything that would pass as reasonable would therefore be the thoughts and experiences that the heterosexual white male deems fit.

Interestingly, in paragraph 9.3.5 the Commission also references this extract by Modiri. The Commission does so when it establishes the requirement of objectivity and context and thus critiques the judgment of Afriforum $v$ Malemastating that 'how the black majority views the song (kiss the boer) should also be interpreted to constitute what the court sees as reasonably' ${ }^{66}$ It is my understanding that the Commission does not apply Modiri's critique of reasonableness properly, as the Commission's request alludes to the black majority's perspective to be assimilated into the already white perspective of reasonable. This type of assimilation would also be rejected by CRT as it alludes to the racist idea that blackness needs to be assimilated into whiteness. ${ }^{67}$

In paragraph 5.6 and 7.1.2.2 of the report the Commission draws reference to the case of Hotz $v$ University of Cape Town where it is stated that:

Where the offender of hate speech belongs to a vulnerable group [...] [f]reedom of speech must be robust and the ability to express hurt, pain and anger is vital, if the voices of those who see themselves as oppressed or disempowered are to be heard. ${ }^{68}$

I have already discussed the issue of racism not being able to be committed by both black and white people, since racism is a consequence of the larger socio-economic inequality in a white supremacist society. ${ }^{69}$ However, the above quotation further illustrates hate speech in its abstract nature. On a superficial level, the quotation can be seen as being empowering towards vulnerable people (which in the context of this essay is black people) yet on a much deeper level, from a CRT perspective, it shows just how

63 Bell (n 4) 901 - 906. See also Modiri (n 37) 284; Modiri (n 14) 247.

64 The SAHRC Report (n 2) 10.

65 Modiri (n 36) 275.

66 The SAHRC Report (n 2) 10. See also Afriforum v Malema 2011 (12) BCLR 1290 (EqC) 39.

67 Bell (n 4) 901 - with an emphasis on 'empower'. See also Modiri (n 36) 284; Modiri (n 13) 225.

68 The SAHRC Report (n 2) 16. See also Hotz v University of Cape Town 2019 (1) SA 369 (CC).

69 Bell (n 4) 901 - 906. See also Modiri (n 36) 288; Modiri (n 13) 233. 
detached hate speech is. The above quotation implies that some people are vulnerable and some are not and this is therefore evidence of racial inequality. Therefore, instead of equality jurisprudence dealing head on with this inequality, hate speech deals with the anger people feel as a result of the much deeper substantive inequality. What the above quotation in essence does is state that the courts should aid people in finding solace in their 'unfreedom-ness' by allowing them to express anger towards the group that oppresses, instead of dealing with the oppression itself. ${ }^{70}$

In paragraph 5.5 of the report, the commission references the case of SARS V CCMA which states that:

It can never be over-emphasised that being called a kaffir is the worst insult that can ever be visited upon an African person in South Africa, particularly by a white person' (emphasis added). ${ }^{71}$

This was said in the context of the Commission illustrating that the identity of both the offender and the target is of importance. From the perspective of CRT one cannot deny that the use of the k-word is an insult insofar as it denotes inferiority to one race and superiority to another. ${ }^{72}$ To say that it is the worst possible insult is a denial of the underlying substantive inequality that gives effect to the supposed inferiority and superiority. Substantive inequality is the essence of white supremacy. Thus from a CRT perspective one would say the very existence of white supremacy is the worst possible insult towards black people. ${ }^{73}$ This is another example of the court's narrow interpretation of racism.

In CRT, the argument is that racism is the systemic, political, economic and social oppression of black people under a system that seeks to promote white privilege and interests i.e white supremacy. Therefore, if black people are not systematically oppressed in a political, economic and social manner for white privilege then racism ill not exist. Race-based hate speech, as a consequence of systemic racism, would also be obsolete. The proposal therefore is to address the substantive inequality of black people instead of addressing hate speech which is merely a concomitant issue. ${ }^{74}$

70 As above.

71 The SAHRC Report (n 2) 16.

72 Bell (n 4) 906. See also Modiri (n 36) 286; Modiri (n 13) 230.

73 Bell (n 4) 901. See also Modiri (n 36) 288; Modiri (n 13) 261.

74 As above. 


\section{From the perspective of Transformative Constitutionalism}

According to Klare, the South African Constitution can be regarded as a post-liberal document in order to distinguish it from a social democratic document, since to Klare, the term 'social democratic' is too narrow an interpretation when one looks at the Constitution's recognition of different races, cultures, genders and languages. ${ }^{75}$

Transformative Constitutionalism entails the long-term development of constitutional jurisprudence parallel to political developments that will result in effective social change. ${ }^{76}$ For Klare, Transformative Constitutionalism is a method that can be utilised by the judiciary to interpret the Constitution in such a way as to give effect to societal change. 77 This notion of Klare's is influenced by Critical Legal Studies which amongst other things, holds the view that the law and politics cannot be separated and that judges make political decisions all of the time. ${ }^{78}$ Judges should therefore be conscious of the political consequences of their decisions. ${ }^{79}$ Transformative Constitutionalism believes that the Constitution can indeed be a tool for societal change. ${ }^{80}$ The Commission's report and the concept of hate speech (in light of a post-apartheid South Africa) can thus be seen as transformative for a variety of reasons. The first, assuming that the Commission falls within the judiciary as a quasijudicial body and that commissioners acted as adjudicators, the report can be regarded as having been acutely aware of its potential political effects, as Klare argues this essential for transformative adjudication. ${ }^{81}$ The report also set out to protect the black oppressed, or vulnerable groups in recognising that whatever recommendation they make with regard to hate speech would have far more reaching effects beyond the matter at hand. ${ }^{82}$ The Commissioners also disagreed with the Afriforum $v$ Malema case as the judgment was, according to them, too positivist and narrow and therefore not a more transformative view on hate speech. ${ }^{83}$

It has been stated that post-apartheid South Africa, by extension the Constitution, is the political liberation of black people. ${ }^{84}$ Political rights that aim to empower black people, or at least vulnerable

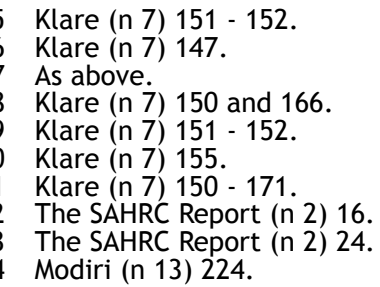


people, are thus seen as transformative. When considering a matter of hate speech, it is stated that one needs to find a balance between freedom of expression and equality. Klare says that the Constitution offer substantive rights and places a positive obligation on the state, ${ }^{85}$ but this is not true for section 2 of the constitution specifically and it is this clause which is the empowering provision for section 10 of PEPUDA, the hate speech clause. All of the aforementioned has been critiqued as political, abstract and detached from the substantively unequal living and working conditions of black people.

Section 3(3) of PEPUDA is another example of how hate speech can be regarded as transformative to a transformative constitutionalist. This section requires, much like transformative constitutionalism, that one considers the historical, social and factual context when adjudicating or presiding over a matter of hate speech. Klare also references these extra-judicial tools for a transformative adjudicator. 86

Thus, although hate speech can be commended as a transformative measure to deal with the scourge of racial and derogatory remarks. It does not do much in changing substantive inequality and this unfortunately goes hand-in-hand with what I believe to be the limits of Transformative Constitutionalism. Merely seeing the law as political ${ }^{87}$ denies it, its socio-economic and substantive racial implications. Murungi states that economic dimensions ought to be recovered in a jurisprudence that aims to truly address the emancipation of black people. ${ }^{88}$

\section{From the perspective of decolonisation}

Decolonisation goes much further than Transformative Constitutionalism in its aspirations to address the legacies of colonialism. Thus, when Klare says that Transformative Constitutionalism goes beyond reform but stays short of a revolution, ${ }^{89}$ it is my understanding that decolonisation goes beyond a revolution. 90

Kwasi Wiredu tells us that conceptual decolonisation is the elimination of certain thinking patterns in our minds that have been imposed on us through the process of colonisation rather than our own reflections on life. ${ }^{91}$ Decolonisation is thus a process of unlearning,

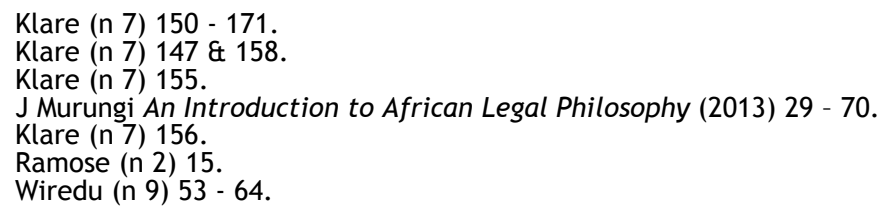


self-consciousness and re-alignment of our conceptual frameworks towards a more African outlook. ${ }^{92}$ Tsenay Serequaberhan's view of African Philosophy as a practice of resistance can also be read as a form of decolonisation in that he requires an indigenous reorientation of philosophical work, a critique of Eurocentrism and the question of our generic identity. ${ }^{93}$

From the perspective of Decolonisation one should be very critical of the Constitution and its ability to transform the South African society, regardless of its interpretation and regard as a Eurocentric document. ${ }^{94}$ I submit that the South African Constitution can be regarded as a Eurocentric document if one looks at the founding values (like equality, which is at the heart of hate speech) and the nature of the fundamental rights it contains.

The founding values of the Constitutional are equality, freedom and dignity. ${ }^{95} \mathrm{~A}$ reading of Bhengu reveals that these three founding values of our Constitution stem from the western philosophical view that one is born a human and therefore deserving of equal treatment, freedom and dignity. ${ }^{96}$ These concepts are also typical of a proWestern individualistic nature, much like hate speech (as has been already critiqued). ${ }^{97}$ The aforementioned is contrary to the African Philosophical notion that one becomes a human through communal interactions. ${ }^{98}$ Further substantiation for the Eurocentricity of the Constitution which gives rise to the concept of hate speech, is that some of the fundamental rights in the Constitution are also similar to those proposed by the western philosopher John Locke which are life, liberty and property. ${ }^{99}$

Furthermore, a possible reason for the abstract nature of equality, and in turn hate speech, would be the narrow view of what constitutes a human being in the western world; the Aristotelian notion that 'man is a rational animal'. ${ }^{100}$ This in turn was not only the basis of the west's conquest of Africa but it also led to a narrow concept of rights as it was deemed that since humans are rational they are to have a very abstract relationship with their environment. The aforementioned is also contrary to the African Philosophical notions of what constitutes a human being. ${ }^{101}$

92 Wiredu (n 9) 55.

93 Serequaberhan (n 9) 44 - 50.

94 As above.

95 The Preamble of the Constitution (n 42).

96 Bhengu (n 14) 4.

97 Modiri (n 36) 406.

98 Ramose (n 1) 12.

99 J Powell 'John Locke: Natural rights to life, liberty and property' 1 August 1996 https://fee.org/articles/john-locke-natural-rights-to-life-liberty-and-property/ [accessed on 26 May 2019].

100 Ramose (n 1) 3.

101 Ramose (n 1) 3 \& 11. 
For a jurisprudence of substantive equality, we would have to decolonise how we perceive human beings and their relationship to their environments. African jurisprudence offers a fundamentally different view on what constitutes a human. If one looks at the concept of Ubuntu we see that one only becomes a human by being a part of something bigger namely, an already existing and continuing communal life that takes into account the living, the living dead and the yet to be born, as Ramose puts it. ${ }^{102}$ It is also from this concept of Ubuntu that the idea is put forth that justice always manifests itself in the concrete world. ${ }^{103}$ Equality would thus be seen in the substantive relations between human-beings. ${ }^{104}$ This is the 'indigenous re-orientation' that Serequaberhan aspires towards in African Jurisprudence. ${ }^{105}$

When reading what the above scholars say about decolonisation and comparing it to what Klare says about Transformative Constitutionalism, one can conclude that Decolonisation is much more a method for reform then merely a theory. An example to this would be the concept of 'reasonableness': the legal requirement for objectivity. 'Reasonableness' has already been critiqued in this essay. Notwithstanding, a Transformative Constitutionalism approach, as had been adopted by the Commission in the report, would assimilate the black majority's perspective into the objective reasonable perspective which is white and Eurocentric. ${ }^{106} \mathrm{~A}$ Decolonisation approach would however do away with the requirement of reasonableness altogether and replace it with a concept like Ubuntu (not the narrow interpretation of Ubuntu that the court follow, but the one as defined by Ramose). ${ }^{107}$

Decolonisation, much like CRT, is more concerned with the root cause of racial inequality, which is colonisation, eurocentrism and white supremacy. ${ }^{108}$ While hate speech laws, even if interpreted through Transformative Constitutionalism, aim to remedy the consequences of racial inequality. The aforementioned can largely be attributed to a narrow interpretation of racism. ${ }^{109}$

102 Ramose (n 1) 4 - 10.

103 Ramose (n 1$) 3$.

104 Ramose (n 1) 3 - 13.

105 Serequaberhan (n 9) 44 - 50.

106 Ramose (n 1) 3.

107 Wiredu (n 9) 53-64. See also Serequaberhan (n 10) 44 - 50.

108 Ramose (n 1) 11 - 13.

109 Ramose (n 1) 13. 


\section{Conclusion}

In conclusion, equality jurisprudence is essential in South Africa, which is said to be the most unequal country in the world. ${ }^{110}$ Section 10 of PEPUDA and the to-be-promulgated Hate Speech Bill form part of South Africa's equality jurisprudence. In this work I have shown, through CRT, that hate speech is an abstract concept within equality jurisprudence. I have shown how Transformative Constitutionalism buys into this abstract notion of equality. I have also shown how decolonisation can be utilised for a more substantive equality jurisprudence.

It is not the intention of this article to brush aside the concept of racially motivated hate speech as frivolous. This article instead aims to critique hate speech as it is considered by the Commission. This article highlights that an effective equality jurisprudence does not fall victim to a narrow interpretation of racism and an abstract notion of equality. An effective equality jurisprudence rather encapsulates a much broader view of racism as systemic and would thus aim to change the lives of black people in a more substantive, concrete and material way.

110 K Pomerantz 'The story behind TIME's cover on Inequality in South Africa' (2 May 2019) https://time.com/5581483/time-cover-south-africa/ (accessed on 16 September 2019). 